\title{
sciforum
}

\section{Global Warming and Climate Change}

\author{
Elba N. Soza, Kathryn Ayres MA, RD, LD/N
}

${ }^{a}$ West Coast University

${ }^{b}$ West Coast University

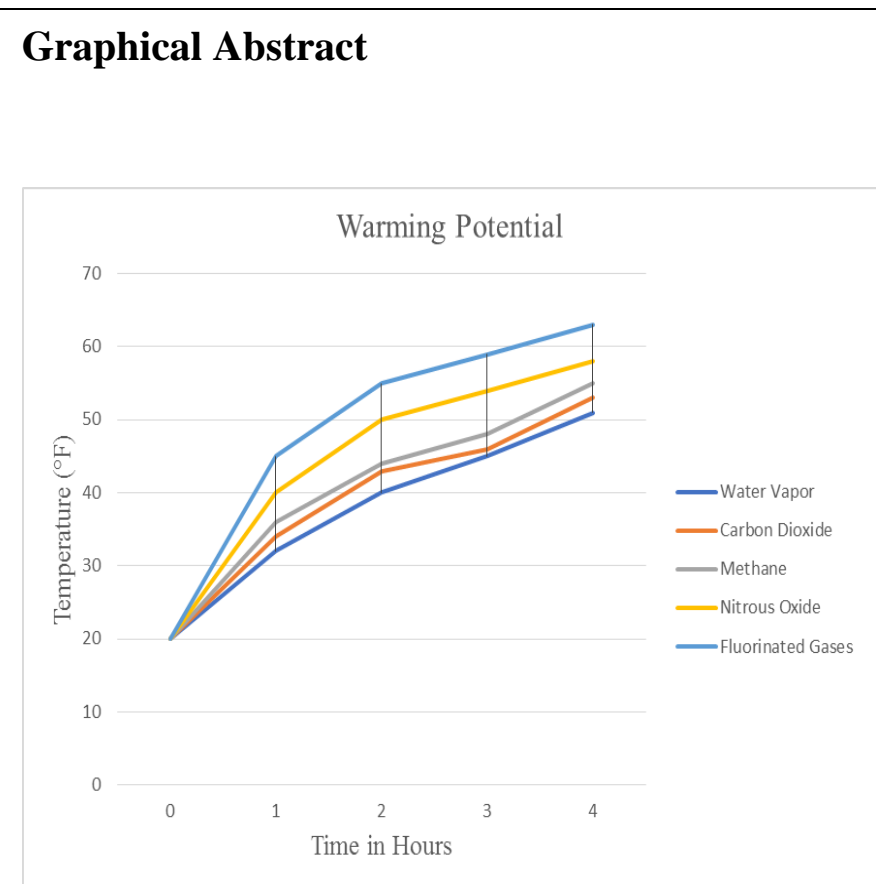

Abstract.

Global warming is defined as an increase in the average temperature of the Earth's atmosphere. Climate change is an effect of global warming that cause drastic changes in the weather. Volcanic eruptions, solar radiation, and movement of crustal plates are some of the natural causes of climate change. Additionally, modern lifestyle is a substantial contributor to climate change. Global warming influenced by society is caused through an increase in greenhouse gases. Some of these gases include water vapor, carbon dioxide, methane, fluorinated gases and nitrous oxide. These gases warm the Earth's atmosphere by trapping heat. Fluorinated gases have the highest warming potential followed by nitrous oxide, methane, carbon dioxide and water vapor. In the environment, water vapor is released in 
enormous amounts followed by carbon dioxide, methane, nitrous oxide and fluorinated gases. Water vapor is a special gas because it has a low warming potential but is released in such high amounts, therefore, it has the highest warming effect. The carbon cycle circulates and transforms carbon back and forth between living species and the environment. Animal agriculture, transportation, and water utilities disrupt the carbon cycle by releasing stored carbon. As a result of global warming the following occur: intense heat, droughts, hurricanes, fires, floods, and rising of the sea level. Researchers created two experiments, the first experiment tested the warming potential of greenhouse gases at a constant rate. In contrast, the second experiment tested the warming potential of greenhouse gases at the rate they are released in the environment. In order to conduct these experiments greenhouses, ice sculptures, lights and thermometers were used. The results stated fluorinated gases had the greatest warming potential, while gases were distributed at a constant rate and carbon dioxide had the greatest warming potential when release in correlation to the environment. In conclusion, global warming is caused by greenhouse gases 
that are released by modern lifestyle. If global warming continues there will be fatal outcomes and congress has the power to prevent this by imposing a law in which methane is taxed.

Insert abstract text here

\section{Introduction}

\section{Global Warming and Climate Change}

Global warming is defined as an increase in the average temperature of the earth's atmosphere (Demir, 2016). Climate change is the impact of global warming; other changes besides the warming of the earth's atmosphere (Global Climate Change, 2008). Droughts, extreme weather, and even the rising sea levels are effects of global warming and climate change (Tait, 2014). These two are related (Demir, 2016).

Since the late 19th century the earth's surface has risen about 2.0 degrees Fahrenheit (Global Climate Change, 2008). Volcanic eruptions, solar radiation, and movement of crustal plates are some of the natural causes of climate change (Climate Science Investigations South Florida-Cause of Climate Change, 2017). When volcanoes erupt, they release carbon dioxide and aerosols (Climate Science Investigations South Florida-Cause of Climate Change, 2017). Aerosol has a cooling effect that lasts for 1-2 years because the aerosol fragment blocks solar radiation (Climate Science Investigations South Florida-Cause of Climate Change, 2017). When the sun's magnetic field moves through the sun it creates sunspots (Climate Science Investigations South Florida-Cause of Climate Change, 2017). The more sunspots the more heat, which causes extreme heat on earth (Climate Science Investigations South Florida-Cause of Climate Change, 2017). Apart from volcanoes and solar radiation, movement of the crustal plates is a contributing natural factor in climate change (Climate Science Investigations South Florida-Cause of Climate Change, 2017). Those movements cause the oceans and air to switch direction affecting the climate of the continents (Climate Science 
Investigations South Florida-Cause of Climate Change, 2017). Modern lifestyle is the cause of unnatural global warming and climate change (Demir, 2016).

Warming of the atmosphere is caused by continued greenhouse effects created by modern lifestyle (Demir, 2016). These gases are also need to keep the balance on Earth and too much can have disrupted effects (What is The Carbon Cycle?, 2017). The greenhouse effect is the ability to trap heat (NASA Climate Kids: What is the greenhouse effect?, 2017). Greenhouses are made of glass (NASA Climate Kids: What is the greenhouse effect?, 2017). The glass allowed sunlight to come in but not to come out. In this way the crops stay warm during the night (NASA Climate Kids: What is the greenhouse effect?, 2017). In the same way, greenhouse gases have the ability to trap heat in the earth's atmosphere (NASA Climate Kids: What is the greenhouse effect?, 2017). Intensification of greenhouse gases depend on the population (Jorgensen, 2006). The environment can only absorb a certain amount of emission (Earth still absorbing about half carbon dioxide emission produced by people: study, 2017). The production not being absorbed remains in the atmosphere and traps the sun's heat (Earth still absorbing about half carbon dioxide emission produced by people: study, 2017). This amount of trapped heat then causes the atmosphere's temperature to rise. (Earth still absorbing about half carbon dioxide emission produced by people: study, 2017). The highest safe level of emissions is around 350 parts per million of carbon dioxide and greenhouse gases in the atmosphere and as of right now we are at 400 (Anderson, 2014).

The principle greenhouse gases are water vapor, carbon dioxide, methane, nitrous oxide, and fluorinated gases (What are greenhouse gases?, 2017). These gases are made up of three or more atoms (The Greenhouse Effect | UCAR Center for Science Education, 2017). When the heat on the surface is released back into the atmosphere these particles absorb the heat (The Greenhouse Effect | UCAR Center for Science Education, 2017). Later the heat bounces to another emission with the same molecular structure (The Greenhouse Effect | UCAR Center for Science Education, 2017). This mechanism helps the earth conserve heat (The Greenhouse Effect | UCAR Center for Science Education, 2017). Fluorinated gases makeup 2\% of the overall production of gas and are eliminated in a few weeks or a thousand years (Climate Change Indicators: Greenhouse Gases | US EPA”, 2017). 
Nitrous oxide produces $16 \%$ and takes 121 years to be disregarded (Climate Change Indicators:

Greenhouse Gases | US EPA”, 2017). Methane is the second largest contributor to global warming, by contributing $16 \%$ of the greenhouse gases (Jorgenson, 2006). Lastly, carbon dioxide contributes $76 \%$ of global emissions and cannot be destroyed over time (What are greenhouse gases?, 2017). Carbon dioxide is released in enormous amounts but has the least warming potential (What are greenhouse gases?, 2017). Above carbon dioxide with correlation to warming potential is methane then nitrous oxide, fluorinated gases and water vapor with the most warming potential (What are greenhouse gases?, 2017).

The circulation and transformation of carbon back and forth between living things and the environment is known as the carbon cycle (What is The Carbon Cycle?, 2017). Carbon cannot be broken down and is present in living and non-living things (What is The Carbon Cycle?, 2017). In the carbon cycle, plants take in carbon dioxide and water, then convert it to oxygen and carbohydrate through a process name photosynthesis (What is The Carbon Cycle?, 2017). The oxygen and carbon are then absorbed by animals (What is The Carbon Cycle?, 2017). The animals later convert those products into carbon dioxide (What is The Carbon Cycle?, 2017). Through the decomposition stage, the remains are either stored on earth as coal, oil, rocks, in soil or they are released into the atmosphere (What is The Carbon Cycle?, 2017). The remaining carbon that is stored on earth is being released by humans into the atmosphere by burning of coal, cutting off the trees and more (What is The Carbon Cycle?, 2017).

Animal agriculture, transportation, and water utilities among other disrupt the carbon cycle. In the process, they release stored carbon that was locked in the surface. A report published by the United Nations stated that raising livestock produces more greenhouse gases than the entire transportation sector (Anderson, 2014). Animal agriculture produces $65 \%$ of the world's nitrous oxide, which has a global warming potential 269 times greater than carbon dioxide per pound, concluding that animal agriculture has a greater potential to harm the environment rather than transportation (Anderson, 2014). Carbon dioxide emissions are expected to increase $20 \%$ by the year 2040 and emissions from agriculture are predicted to increase $80 \%$ by the year 2050 (40\% by the year 2040) (Anderson, 2014). 
This is all due to a projection of an increase in meats and dairy consumption (Anderson, 2014). Raising animals is also responsible for $30 \%$ of the water consumption (Anderson, 2014). Hydraulic fracturing for natural gas use 100 billion gallons of water every day but raising livestock uses 34 trillion gallons (Anderson, 2014). It takes 477 gallons of water to produces eggs, 900 gallons to produce cheese and 1 Quarter Ponder takes 660 gallons of water to make. The water needed to make a burger could be used to take a shower for two months (Anderson, 2014). Apart from water usage raising animals utilizes $45 \%$ of the Earth's land (Anderson, 2014). Ninety-one percent of the destruction of the Amazon rainforest is due to raising livestock (Anderson, 2014). Additionally, raising animals is the leading cause of dead zones, habitat destruction and even species extinction (Anderson, 2014). Animal agriculture is responsible for $51 \%$ of human-caused climate change.

When the carbon balance is disturbed global warming and climate change occur. Global warming then causes direct and indirect effects (Tait, 2014). The direct effects being natural disasters that include: intense heat, droughts, hurricanes, fires, floods, and rising of the sea level (Tait, 2014). In recent years, the number of heat waves has increased (Menu, 2017). Texas and Oklahoma experienced more than 100 days over 100 degrees Fahrenheit in 2011 (Menu, 2017). The indirect effects are systemic (Tait, 2014). The ecosystem and its cycles have been affected (Tait, 2014). Living organisms in the ecosystems are being affected as well (Tait, 2014). Finally, there are physical properties, for example, pollution, ozone and soil moisture (Tait, 2014).

In the past century, the global sea level has been rising at a rate of one-eighth of an inch per year (US Department of Commerce, National Oceanic and Atmospheric Administration, 2008). As a result of the sea level rising there is documentation of an increase in nuisance flooding (US Department of Commerce, National Oceanic and Atmospheric Administration, 2008). There are two causes of global sea level rising, the warming of the ocean and the melting of land-based ice (US Department of Commerce, National Oceanic and Atmospheric Administration, 2008). The ocean is absorbing more than $90 \%$ of the atmospheric heat and therefore, are becoming warmer (US Department of Commerce, National Oceanic and Atmospheric Administration, 2008). The air being absorbed by the ocean contains excessive amounts of greenhouse gases (Climate Change Indicators: 
Oceans, 2016). These emissive amounts of emission are causing the oceans to become more acidic causing the endangerment of ocean life (Climate Change Indicators: Oceans, 2016). The energy being absorbed by the ocean will later be returned to the air and the cycle will continue (Runyan, 2001).

The climate change creates an opportunity for natural disasters to occur. Researchers have linked tropical storm intensity with ocean temperature (US Department of Commerce, National Oceanic and Atmospheric Administration, 2013). The warmer the ocean, the more possibilities that a hurricane will occur (US Department of Commerce, National Oceanic and Atmospheric Administration, 2013). Warm water and moist air create a tropical storm (How do hurricanes form?:: NASA Space Place, 2017). When evaporation takes place in an ocean with warm water the surrounding air at higher pressure is pushed to the lower pressure (How do hurricanes form?:: NASA Space Place, 2017). This air becomes warm and induces more surrounding air to repeat the process creating a swirl (How do hurricanes form?::NASA Space Place, 2017). Later, the air that cools off forms a cloud and the cycle keeps on growing (How do hurricanes form?:: NASA Space Place, 2017). The storm continues to grow if it has warm water and low winds (US Department of Commerce, National Oceanic and Atmospheric Administration, 2013). A storm with massive potential is called a hurricane and usually moves towards land (Hurricane, 2017). There are 5 categories for a hurricane, they are based on wind speed and have different damaging capacities (How do hurricanes form?:: NASA Space Place, 2017). Hurricanes can occur in many parts of the world and some months are more likely to have a hurricane than others (Hurricane, 2017). Hurricanes also induce heavy winds, rainfalls, cause property damage and most importantly lives are lost (Hurricane, 2017).

There are many ways in which individuals can contribute to the decrease in global warming but how can they start if they do not believe. Non-believers report that nature induces climate change and that humans have nothing to do with it (Admin, 2017). Nature does induce climate change but if nature is unbalanced then there will be an unbalance in climate change (What is The Carbon Cycle?, 2017). Concluding, global warming is due to human activities because they are altering natural processes like the carbon cycle (What is The Carbon Cycle?, 2017). However, skeptics are also pronouncing that climate scientists are bias like the public (Idso, Carter \& Singer, 2015). Measurements that are 
collected by scientists demonstrate that global warming and climate change is real (Scientific consensus: Earth's climate is warming, 2017). They are measuring surface air temperature and subsurface ocean temperature to make a conclusion (Scientific consensus: Earth's climate is warming, 2017). Facts do not lie, annual and decadal average temperature is increasing (Oppenheimer, 2015). Climate change will induce sea level rising and storm intensity (Oppenheimer, 2015). From 1950 to 2012 there was an increase in storm surge, tide level, and high water attribute to sea level rise (Oppenheimer, 2015). Finally, there are many ways in which individuals can contribute to the decrease in global warming but how can they start if they do not believe.

\section{Materials and Methods}

\section{Materials and Methods}

To determine which greenhouse gas has the most warming potential, this first experiment was conducted. The first experiment was conducted in a four-hour period. Four identical greenhouses 30 inches in length, 30 inches in width, and 48 inches in height were used. Each greenhouse was covered with IR Poly 6 Mil Sheeting; this sheet allowed for the light to go in but not out. The back of the greenhouses were painted black, to absorb heat. Each greenhouse had a table to be placed on top of. The tables were all 20 inches in height, 35 inches in length and 35 inches in width. The researchers used Elegance ICE to make them four ice sculptures 15 inches in length, 15 inches in width and 20 inches in height. One ice sculpture was equivalent to 50 pounds and its recorded temperature was 20 degrees Fahrenheit. The ice sculptures were the same weight, size, height, length, and width. Four identical Yongnuo 300-11l LED lights were used to heat the greenhouse. Four timers were used to record the time in which it took for each ice sculpture to melt. Four thermometers were used in this experiment to measure the temperature inside the greenhouses. The four gases used were carbon dioxide, methane, water vapor and nitrous oxide. Each gas was used, in the same quantity.

To determine which greenhouse gases had a greater effect on the environment, this second experiment was conducted. In the second experiment, the same materials were used but the number of 
gases being released were decreased or increased depending on the way they are used in the environment. Carbon dioxide was release at 365 ppm, methane at 1745 ppb, nitrous oxide 314 ppb, fluorinated gases at a rate of 98.2 and for water vapor the greenhouse was left with normal air volume.

This first experiment was conducted in the following manner. All the boxes were positioned on top of their designated table. Directly in front of the boxes, the Yonfnuo 300-11l LED lights were positioned. The lights were all directed at the same angle facing the greenhouses. Each box was placed 12 feet away from the greenhouses, with the same amount of light going inside of each box. During this experiment, it was critical that everything was identical. Each box contained a thermometer placed inside the box, which calculated the temperature while the gases went in. The ice sculptures were then put inside the boxes, right in the center facing the light. Right after the timer was started, the greenhouse gases were released into the boxes. Carbon dioxide, methane, water vapor and nitrous oxide were all released at the same rate and in the same amount. The last greenhouse did not receive any type of gas; it was used as the control. The researchers then recorded the data as the ice sculptures melted.

To determine which greenhouse gases had a greater effect on the environment, this second experiment was conducted. For the second experiment, all the procedures were identical for the exception of the number of gases going in the greenhouses. Carbon dioxide was released at $82 \%$, methane at $10 \%$, and lastly, nitrous oxide at $5 \%$. This experiment was used to analyze the effects of greenhouse gases in our environment.

\section{Results and Discussion}

In the first experiment data showed that fluorinated gases increasing temperature more than any other gas. Fluorinated gases started at a temperature of 20 Fahrenheit and in one hour increases to 45 degrees Fahrenheit. In the 2nd hour, the temperature rose from 45 to 55 degrees Fahrenheit and in the third hour from 55 to 59 degrees Fahrenheit. Finally, in the fourth hour from the temperature increased from 
55 to 63 degrees Fahrenheit by which the ice sculpture was completely melted. Nitrous oxide had the second most powerful warming potential, which had 5 degrees less than fluorinated gases for every recorded increment. Nitrous oxide started at a temperature of 20 degrees and increase from 20 to 40 to 50 to 54 and finally to 58 . Methane, had the third most powerful warming potential, with a starting temperature of 20 that increase to 36 , then to 44 , then to 48 , and finally to 55 . Carbon dioxide has the four most powerful warming potential starting at 20 degree Fahrenheit and increasing to 34, then to 43, then to 46, and finally to 53. Lastly, the control which was water vapor had the least warming potential, starting at 20 just like the others. Water vapor increased from 20 to 32 to 20 to 45 and finally to 51 .

In the second experiment Carbon dioxide had the most warming potential. Carbon dioxide started at a temperature of 20 degrees Fahrenheit and increase to 43 in once hour. In the second hour temperature increased from 43 to 54 and then in the third hour temperature increase from 54 to 57 . Finally, temperature boosted from 57 to 60 in the last hour, by which the ice sculpture was completely melted. Methane and carbon dioxide were close in temperature; the temperature were no more than 5 degrees Fahrenheit apart. Methane started at 20 degrees Fahrenheit and increase to 40 then to 49 then to 55 and finally to 57. Nitrous oxide had the third most warming potential with a starting point of 20 that increase to 33 , then to 44 , then to 53 , and finally to 55 . Fluorinated gases and nitrous oxide were very close; the temperature were no more than 2 degrees Fahrenheit apart. Fluorinated gases started at 20 and increase to 33 , then to 42 , then to 52 , and finally to 53 . In this experiment water vapor also came last. Water vapor started at 20 degrees Fahrenheit and continued to increase to 32 , then to 40, then to 45 , and finally to 51 .

\section{Conclusions}

The conducted experiments revealed that greenhouse gases have the ability to retain heat and eventually make an environment warmer. Fluorinated gas had the highest warming potential. Those gases are extremely harmful compared to any other gases in regards to climate change. In the first hour, there was a dramatic increase the temperature from 20 to 45 degrees Fahrenheit. Nitrous oxide's global warming potential is almost as harmful as fluorinated gases; the difference was slight. Nitrous 
oxide remained 5 degrees lower than fluorinated gases throughout the experiment. Carbon dioxide and methane increased temperature but have less warming potential than the other gases. These two gases had very close temperatures; they differentiated by no less than 2 degrees in each recorded interval. Water vapor was the only greenhouse gas that did not increase the temperature greatly. In the first hour, the temperature merely increased 12 degrees. Water vapor had the least warming potential, which is not correct. In this small scaled experiment the intensity of water vapor could not be presented because water vapor needs to be combined with other greenhouse gas in order to display its maximum potential.

Results were reversed in the second experiment for the exception of water vapor; as stated before it does not have the necessary components to fully manifest itself. Carbon dioxide had the most warming potential because it was released in massive amounts. Methane had close temperatures to carbon dioxide because it had a similar effect and it was distributed in large amounts as well. Nitrous oxide and fluorinated gases had close temperatures even though nitrous oxide is distributed in higher amounts than fluorinated gases. Their temperatures were close because fluorinated gases had an extraordinary potential.

Based on the research and data there is no doubt that global warming exists and human activity is the cause. Carbon dioxide, methane, nitrous oxide, fluorinated gases and water vapor among other are heating the earth's atmosphere. Global warming then causes a cascade of events. If the this is not stopped or reduced in any ways, there will be further worldwide implications. The environment and future generations will suffer the consequences. Temperatures will continue to rise will as those particles are released. There will be changes in precipitation patterns going from high to low. The number of droughts and heat waves will increase. Hurricanes will also become stronger and more intense because of the ocean warming. Melting of ice glaziers will increase sea levels. All living things will be induced to adapt. In the process the crop production will be damaged because of harsh environments. Humans will be forced to adapt to environmental changes by migrating to other areas. Temperature changes will allow harmful microorganism to survive and harm humans. Just like any other balance when disrupted, there are consequences. 
The United States is a large contributor of greenhouse emissions ("The Natural Resources

Defense Council (NRDC)," 2017). In fact, it is the world's second largest carbon polluter ("The Natural Resources Defense Council (NRDC),” 2017). In September 2016, president Barack Obama signed the Paris Climate Agreement (“The Natural Resources Defense Council (NRDC),” 2017). This agreement was made to decrease climate change pollution in an attempt to better our future ("The Natural Resources Defense Council (NRDC)," 2017). One hundred ninety-five countries have signed the agreement and only two are non-participants ("The Natural Resources Defense Council (NRDC)," 2017). Currently in the United States, President Donald Trump made the decision to withdraw the country from the Paris Climate Agreement ("The Natural Resources Defense Council (NRDC)", 2017). The United States is the second largest contributors of carbon polluters, us withdrawing from the agreement will essentially impact the attempt of other countries to reduce emissions ("The Natural Resources Defense Council (NRDC)," 2017). Withdrawing from the agreement will also undo the progress we have made as a nation ("The Natural Resources Defense Council (NRDC)," 2017). This catastrophe will destroy the jobs of many and the severely impact the lives of the future generations (“The Natural Resources Defense Council (NRDC)," 2017). Over all this decision on a global scale will have horrible impacts and it makes the United Sates appear mindless and uncooperative to global warming effect.

Methane is the second largest contributor to global warming; therefore, taxation of methane shall be enforced depending on the type by-product. Dairy products will be taxed at a rate of $5 \%$. These dairy products are produce from cows which produce an immense amount of methane emission. Chicken and quail will be taxed at a rate of 5\%, and beef will be taxed at a rate of $9 \%$. The grocery stores will be required to donate leftover food, in order to reduce methane production from excess waste. Electricity will be taxed at a rate of $7 \%$ in order to reduce the use and burning of coal. These laws will reduces the methane emissions by $10 \%$ percentage. Consumers try to pay the least amount of money for their products, and by increasing the price it will force consumers to cut down and only buy little amounts. Taxing the by-products of methane production will benefit the world in many ways. For one reason, global warming will be reduced by the decrease in methane emissions and 
the decrease will cause less natural disasters to occur. Another benefit of taxing methane will be the reduction of chronic illness. Buyer will be pushed into consuming plant based foods. Vegetable, fruits, whole grains, and legumes are healthy source of food and will improve your overall health. Eating plant based foods will decrease the risks of getting hypertension, heart disease, atherosclerosis, and other very serious diseases. The meat and dairy industry will lobby against this law because it will damage its profits. The agriculture industry will most likely claim that global warming is not real and there is no need to make a new law, but as shown in the experiment and throughout this paper, global warming is real.

If this policy is not enforced, it will devastate the world. Nurses are required to nurse those who are ill and refrain from anything that is not good. Health care facilities will eventually become overpopulated with patients that need treatment. Natural disasters will produce a massive number of injured patients and will bring new illness to the population. Polluted air will insidiously increase the number of lung disease cases. Water pollution will also be cause damage to the organ systems of many individuals. Doctors, nurses, and staff will be the most exposed and affected by many of these diseases because they are the ones treating the patients.

It is extremely important for Congress to approve this law. It is a great importance to our lives, future generations, the environment, and many more.

\section{References}

\section{References}

Admin, C. (2017). Home. Climate Change Reconsidered. Retrieved 12 November 2017, from

\section{http://climatechangereconsidered.org}

Aksan, Z., \& Celikler, D. (2015). Evaluation of knowledge and Misconceptions of Science

Teacher Candidates in Turkey Regarding the Greenhouse Effect Through the Use of Drawings. Journal of Education and Practice, 6(13),112-120. 
Anderson, K. (Producer), \& Kuhn, A. (Director). (2014). Cowspiracy: The Sustainability Secret

[Motion picture]. United States: A.U.M. Films First Spark Media.

The Carbon Cycle, the Greenhouse Effect, and Ways to Reduce Emissions. (n.d.). Retrieved

November 02, 2017, from https://teeic.indianaffairs.gov/er/carbon/carboninfo/index.htm

Climate Change Indicators: Greenhouse Gases|US EPA. (2017). US EPA. Retrieved 10 November

2017, from https://www.epa.gov/climate-indicators/greenhouse-gases

Climate Change Indicators: Oceans. (2016, August 02). Retrieved November 03, 2017, from

https://www.epa.gov/climate-indicators/oceans

Climate Science Investigations South Florida - Causes of Climate Change. (2017). Ces.fau.edu.

Retrieved 10 November 2017, from http://www.ces.fau.edu/nasa/module-4/causes/methanecarbon-dioxide.php

Demir, P., \& Avgin, S. S. (2016). Global Warming and Measures to Be Taken: Pre-Service Science

Teachers' Views. Journal of Education and Practice, 7(27), 128-135.

Earth still absorbing about half carbon dioxide emissions produced by people: study.

(2017). Phys.org. Retrieved 10 November 2017, from https://phys.org/news/2012-08-earthabsorbing-carbon-dioxide-emissions.htm

The Greenhouse Effect | UCAR Center for Science Education. (2017). Scied.ucar.edu. Retrieved 10 November 2017, from https://scied.ucar.edu/longcontent/greenhouse-effect

Trump's Withdrawal from the Paris Climate Agreement Is a Grave Mistake. (2017). NRDC. Retrieved

3 December 2017, from https://www.nrdc.org/experts/nrdc/trumps-withdrawal-paris-climateagreement-grave-

mistake?gclid=CjwKCAiAu4nRBRBKEiwANms5W3Dee_WV31J1H675wjtWOSBpP4zTp6x 9bi3wUKa9o18GSYSej_rKMRoCzFYQAvD_BwE

Global Climate Change: Evidence. (2008, June 15). Retrieved November 02, 2017, from

http://climate.nasa.gov/evidence/

How do hurricanes form? :: NASA Space Place. (2017). Spaceplace.nasa.gov. Retrieved 12 November 2017, from https://spaceplace.nasa.gov/hurricanes/en/ 
Hurricanes. (n.d.). Retrieved November 03, 2017, from https://www.ready.gov/hurricanes

Idso, C., Carter, R., \& Singer, S. (2015). Why scientists disagree about global warming.

Jorgenson, A. (2006). Global Warming and the Neglected Greenhouse Gas: A Cross-National Study of the Social Causes of Methane Emissions Intensity, 1995. Social Forces, 84(3), 1779-1798.

Korsager, M., \& Slotta, J.D. (2015). International Peer Collaboration to Learn about Global Climate Changes. International Journal of Environmental and Science Education, 10(5), 717-736

Menu. (n.d.). Retrieved November 05, 2017, from http://nca2014.globalchange.gov/highlights/reportfindings/extreme-weather

NASA Climate Kids :: What is the greenhouse effect?. (2017). Climatekids.nasa.gov. Retrieved 10 November 2017, from https://climatekids.nasa.gov/greenhouse-effect/

Oppenheimer, M. (2015). Adapting to Climate Change: Rising Sea Levels, Limiting Risks. Social Research, 82(3), 673-680.

(n.d.). Retrieved November 02, 2017, from https://spaceplace.nasa.gov/hurricanes/en/

Runyan, C. (2001). Ocean Warming Studies Bolster Evidence of Human Climate Change. World Watch, 14(4)10.

Scientific consensus: Earth's climate is warming. (2017, October 18). Retrieved November 05, 2017, from https://climate.nasa.gov/scientific-consensus/

Tait, P.W. (2014). A critical decade for public health: responsibility for energy transitions. Australian \& New Zealand Journal of Public Health, 38(1), 4-6. doi:10.1111/1753-6405.12187

US Department of Commerce, National Oceanic and Atmospheric Administration. (2013, May 29). How does the ocean affect hurricanes? Retrieved November 03, 2017, from http://oceanexplorer.noaa.gov/facts/hurricanes.html

US Department of Commerce, National Oceanic and Atmospheric Administration. (2008, October 27). Is sea level rising? Retrieved November 03, 2017, from https://oceanservice.noaa.gov/facts/sealevel.html

What are greenhouse gases?. (2017). What's Your Impact. Retrieved 10 November 2017, from https://whatsyourimpact.org/greenhouse-gases 
